\title{
Impacts of a New Solar Radiation Parameterization on the CPTEC AGCM Climatological Features
}

\author{
H. M. J. Barbosa, T. A. Tarasova, ${ }^{*}$ and I. F. A. Cavalcanti \\ Centro de Previsão de Tempo e Estudos Climáticos, Cachoeira Paulista, São Paulo, Brazil
}

(Manuscript received 17 April 2007, in final form 1 September 2007)

\begin{abstract}
The impacts of improved atmospheric absorption on radiative fluxes, atmospheric circulation, and hydrological cycle for long-term GCM integrations are investigated. For these runs the operational version of the Centro de Previsão de Tempo e Estudos Climáticos (CPTEC) AGCM and its enhanced version with a new solar radiation scheme are used. There is an $8 \%$ increase in the annual mean global average atmospheric absorption in the enhanced integration as compared with the operational model integration. The extra absorption is due to gases $(0.5 \%)$, the water vapor continuum $(1.5 \%)$, and background aerosols $(6 \%)$, which were not considered in the operational solar radiation scheme. Under clear-sky conditions the enhanced model atmospheric absorption is in agreement with observations to within $\pm 3 \mathrm{~W} \mathrm{~m}^{-2}$, while for all-sky conditions the remaining errors are related to unaccounted-for cloud absorption. There is a general warm-up of the atmosphere in the enhanced model with temperatures increasing up to $\sim 3 \mathrm{~K}$ in the troposphere and $\sim 5-8 \mathrm{~K}$ in the stratosphere, bringing the model closer to the reference values. The intensities of the tropospheric jets are reduced by $7 \%-8 \%$, while that of the polar night stratospheric jet is increased by $5 \%-10 \%$, reducing the model systematic error. The reduced availability of latent energy for the saturated convective processes weakens the meridional circulation and slows down the hydrological cycle. The model overestimation of December-February precipitation over the South Pacific convergence zone (SPCZ) and the South Atlantic convergence zone (SACZ) is reduced by $0.5-1.0 \mathrm{~mm}^{-1 a y^{-1}}$, and that over the Northern Hemisphere storm-tracks region is reduced by $0.5 \mathrm{~mm} \mathrm{day}{ }^{-1}$. On a monthly time scale, the changes in the precipitation distribution over the SACZ are found to be much larger, $\pm 2-3 \mathrm{~mm}^{\mathrm{day}}{ }^{-1}$.
\end{abstract}

\section{Introduction}

General circulation models are used in climate simulations to study climate variability and climate change, and for seasonal forecasting. For all of these applications, it is crucial that a model simulates well the observed climate and its variability. In this sense, the results of long-term integrations are used to show the ability of different models in representing observed characteristic features of the atmospheric circulation and precipitation (Hurrell et al. 1998; Gates et al. 1999; Johns et al. 1997; Pope et al. 2000). These are important

\footnotetext{
* Additional affiliation: Institute of Atmospheric Physics, Russian Academy of Sciences, Moscow, Russia.

Corresponding author address: Dr. Henrique Barbosa, Centro de Previsão de Tempo e Estudos Climáticos, Rodovia Presidente Dutra, Km. 40, 12630-000, Cachoeira Paulista, SP, Brazil. E-mail: hbarbosa@cptec.inpe.br
}

for providing a model climatology and performing model validation, as well as for giving confidence for its applicability. Long-term integrations are also used for comparing different climate models (e.g., Atmospheric Model Intercomparison Project, AMIP; Gates 1992; Gates et al. 1999). The comparison of GCMs shows that they overestimate by $20-42 \mathrm{~W} \mathrm{~m}^{-2}$ the global net surface insolation when compared with ground measurements (Wild et al. 1995; Wild and Ohmura 1999; Wild 2005) and satellite-derived surface solar radiative fluxes (Cess et al. 1995; Li et al. 1997; Cusack et al. 1998; Tarasova and Cavalcanti 2002).

If the systematic errors in the global net surface insolation from GCMs are reduced or eliminated, the effects on atmospheric and oceanic circulations are substantial (Kiehl 1994). For instance, an increase in shortwave absorption in the tropical atmosphere by $25 \mathrm{~W} \mathrm{~m}^{-2}$ enhances the meridional transport of moist static energy by approximately $50 \%$ (Kiehl 1994). Moreover, as the terms for insolation and latent heat flux dominate the heat balance of the tropical oceans 
(Monin 1986), the latent heat flux has to decrease by roughly the same amount as the surface insolation to maintain the energy balance. This corresponding reduction in evaporation significantly affects the state of the tropical troposphere (Kiehl et al. 1995), reducing the convectively available potential energy and decelerating the Walker circulation and hydrological cycle (Collins 2006). However, there is no agreement about the magnitude of the changes in the temperature and wind fields, nor in the hydrological cycle.

In the early 1990 s, Hart et al. (1990) used the Australian Bureau of Meteorology Research Centre's (BMRC) spectral model to demonstrate the impact of changes in physical parameterizations on perpetual January and July integrations. They found, for runs with an enhanced radiation scheme, that the winter stratosphere temperature cold bias was reduced from $-30 \mathrm{~K}$ to less than $-20 \mathrm{~K}$. Moreover, there was a significant improvement in the intensity of the polar night jet, which showed a clear separation from the tropospheric jet. However, Hart et al. (1990) noticed that good descriptions of the upper troposphere and stratosphere zonal wind and temperatures depend not only on the radiative processes but also on the deep and shallow convection, vertical diffusion, and horizontal resolution.

Morcrette (1990) evaluated the impacts of improvements in the radiation and in-cloud properties upon the climate of the ECMWF model. Unlike other GCMs, the ECMWF model used to overestimate the atmospheric absorption of solar radiation by $15 \%-20 \%$ and underestimate the longwave cooling by $10 \%-15 \%$. By replacing the radiation scheme, Morcrette found that the bias of the atmospheric absorption of the solar radiation was reduced to less than $+5 \%$ while the meridional circulation and the hydrological cycle, that is, both precipitation and evaporation, became $15 \%$ stronger.

More recent studies have investigated the response of GCMs to smaller updates in the radiation schemes and hence found a weaker response from the hydrological cycle. For instance, to study the climatic effects of an improved atmospheric absorption Lohmann and Bennartz (2002) integrated the ECHAM4 with two water vapor broadband absorption functions, based on the High Resolution Transmission Molecular Absorption Databases (HITRAN-92 and HITRAN-2K; Rothman et al. 2003). They found that the global-mean atmospheric shortwave absorption increased by $3.2-3.7 \mathrm{~W}$ $\mathrm{m}^{-2}$ while the surface insolation decreased by $2.1-2.5$ $\mathrm{W} \mathrm{m}{ }^{-2}$. As a consequence of the increased atmospheric stability and the reduction in surface fluxes, the hydrological cycle decreased slightly in strength, with a reduction in the global precipitation of $0.07 \mathrm{~mm}^{\text {day }}{ }^{-1}$.
Collins et al. (2006) did a similar study using the Community Atmospheric Model (CAM). The original water vapor broadband absorption function (Briegleb 1992), based on the 1982 U.S. Air Force Geophysics Laboratory (AFGL) molecular absorption database of Rothman et al. (1983), was updated to a function based on the HITRAN-2K database (Rothman et al. 2003). The absorption by the water vapor continuum (Clough et al. 2005) was also included. They found that the atmospheric absorption increased by $3.4 \mathrm{~W} \mathrm{~m}^{-2}$ while the surface insolation decreased by $2.8 \mathrm{~W} \mathrm{~m}^{-2}$. Moreover, the change in the surface insolation was balanced primarily by a reduction of the latent heat and the hydrological cycle was weakened by $2 \%$ (global precipitation falls by $0.05 \mathrm{~mm}$ day $^{-1}$ ).

Other studies have changed the atmospheric absorption in the cloudy atmosphere only, trying to model the enhanced shortwave absorption observed in cloudy conditions. Kiehl et al. (1995) modified the NCAR Community Climate Model (CCM2) to increase the cloud absorption through ad hoc changes in the singlescattering albedo of cloud particles. They found that the extra absorption stabilized the tropical convective atmosphere and caused a 3-4-K warming of the upper tropical troposphere. The increased stability reduced the convective activity and resulted in a weaker Walker circulation.

In a similar study, Collins (2006) modified the absorption effects of clouds by empirically changing the vertical profiles of the heating rates in the NCAR Climate System Model (CSM). He found that the upper tropical troposphere temperature increased as much as $5 \mathrm{~K}$ near $100 \mathrm{hPa}$, due to the increase in the all-sky heating rates by as much as $1 \mathrm{~K}$ day $^{-1}$ at the same altitude. As a consequence of the new vertical profile of the temperature, the cloud cover decreased by $10 \%-$ $15 \%$ at high levels and increased by $5 \%-15 \%$ at middle and low levels. At the same time, the latent heat flux over the tropical western Pacific Ocean was reduced by as much as $20-40 \mathrm{~W} \mathrm{~m}^{-2}$.

The AGCM of the Brazilian Center for Weather Forecast and Climate Studies (Centro de Previsão de Tempo e Estudos Climáticos: CPTEC) is used for weather and climate forccasting. It is a new global Eulerian spectral model (see section 2) based on the CPTEC-Center for Ocean-Land-Atmosphere Studies (COLA) GCM described by Cavalcanti et al. (2002). To improve the model surface flux representation, the $k$-distribution formulation for water vapor solar absorption of Davies (1982) was replaced by that of Ramaswamy and Freidenreich (1992). Chagas et al. (2004) found some minor improvements in the surface fluxes, with a reduction in the bias of the all-sky surface flux 
from +20 to $+16 \mathrm{~W} \mathrm{~m}^{-2}$ (yearly averages for one $20-\mathrm{yr}$ integration).

To further improve the atmospheric absorption of solar radiation by gases and aerosols, a sophisticated shortwave radiation scheme developed by Chou and Suarez (1999) and modified by Tarasova and Fomin (2000), referenced later as CLIRAD-SW-M, was implemented by Tarasova et al. (2006) in the CPTEC-COLA model. This scheme considers the fine effects of gaseous absorption and particle scattering which were not considered in previous versions of the CPTEC-COLA model. The modified code CLIRAD-SW-M also takes into account the water vapor continuum absorption model proposed by Clough et al. (1989). Tarasova et al. (2006) did an initial validation of the new scheme outside of the framework of the global model and showed that the differences between CLIRAD-SW-M and the line-by-line (LBL) reference results of Fomin and Gershanov (1996) were on the order of $1-2 \mathrm{~W} \mathrm{~m}^{-2}$ for clear-sky, and $6 \mathrm{~W} \mathrm{~m}^{-2}$ for cloudy atmospheres. They also integrated the global model for December-February (DJF) 2002-03 and found that the surface fluxes were significantly improved over South America. In particular, the excessive solar radiation biases at the surface were reduced from $30-80$ to $10-30 \mathrm{~W} \mathrm{~m}^{-2}$. As compared with Global Precipitation Climatology Project data (GPCP v2; Adler et al. 2003), the modelsimulated magnitude of precipitation was improved over the equatorial Atlantic Ocean and southeastern Brazil.

This paper reports on the improvements achieved with the new shortwave radiation scheme on the radiation balance, the atmospheric circulation, and the hydrological cycle of the new CPTEC AGCM. The impacts on the hydrological cycle are studied over different time scales and the sources of the differences between the new model and the observations are investigated. To evaluate the model's sensitivity to each of the changes in the solar radiation absorption, we introduce the changes one by one and compare the model results with satellite-derived observations and National Centers for Environmental Prediction-National Center for Atmospheric Research (NCEP-NCAR) reanalysis. Our results are particularly relevant to the ongoing investigation on the global climate response due to changes in the shortwave absorption of the atmosphere-either to correct model biases or to simulate future loadings of aerosol and greenhouse gases.

This paper is divided as follows: Section 2 gives a brief description of the CPTEC model and the new shortwave radiation scheme. The experiment design and data used for model validation are given in section 3. Section 4 is devoted to the comparison of the model climatology and the observations, and section 5 presents the discussion. Conclusions and future perspectives are presented in section 6 .

\section{Short description of the CPTEC AGCM}

The CPTEC AGCM is a global Eulerian spectral model that is based on the CPTEC-COLA model (Cavalcanti et al. 2002). This new model has been operational since 2004. An overview of the global climate simulated with the CPTEC-COLA model is given by Cavalcanti et al. (2002). They have shown that the model simulates reasonably well the main features of global climate, as well as the seasonal variability of the main atmospheric variables. The most important difference between the original CPTEC-COLA model and the currently operational CPTEC model is a change in the water vapor solar radiation absorption (Chagas et al. 2004). Other modifications are related to its computer efficiency and do not change the model climatological features.

The model physical processes include the vegetation module the Simple Surface Biosphere Model (SSiB; Xue et al. 1991); second-order closure turbulent vertical diffusion following Mellor and Yamada (1982); shallow cumulus effects following Tiedtke (1984); Kuo's (1974) and Anthes's (1977) deep cumulus convection scheme; large-scale precipitation produced from the removal of supersaturation; longwave radiation following the work of Harshvardhan and Corsetti (1984), including the scheme of Harshvardhan et al. (1987) to represent the diurnal cycle; and the cloud-radiation interaction of Slingo (1987) and Hou (1990).

\section{a. The operational SW scheme}

The operational shortwave scheme follows the parameterizations of Lacis and Hansen (1974) with the 11-exponential-term $k$-distribution formulation of $\mathrm{Ra}$ maswamy and Freidenreich (1992), which replaced the $k$-distribution formulation of Davies (1982) originally used in the CPTEC-COLA model. This replacement improved the heating rate profiles (Plana-Fattori et al. 1997) and the surface fluxes (Chagas et al. 2004). Nonetheless, this scheme only takes into account the absorption lines of $\mathrm{H}_{2} \mathrm{O}$ and $\mathrm{O}_{3}$, Rayleigh scattering, and cloud reflection, neglecting atmospheric extinction due to $\mathrm{O}_{2}$, $\mathrm{CO}_{2}$, aerosols, and the water vapor continuum. The solar radiation absorption by water vapor is computed with the broadband absorption function of Yamamoto (1962), which underestimates the water vapor absorption when compared with the HITRAN-96 spectroscopic database of Rothman et al. (1998). 


\section{b. The new SW scheme}

The new shortwave scheme, CLIRAD-SW-M, is a modified version of the parameterization of Chou and Suarez (1999). The code was modified by Tarasova and Fomin (2000) to take into account the water vapor continuum absorption model proposed by Clough et al. (1989). This was done by changing the water vapor $k$ distribution functions in the near-infrared bands. The magnitude of the continuum absorption is about $6 \%$ of the water vapor line absorption. The new scheme includes the absorption due to major and minor absorption bands of $\mathrm{H}_{2} \mathrm{O}, \mathrm{O}_{3}, \mathrm{O}_{2}$, and $\mathrm{CO}_{2}$. The magnitude of the absorption in the minor bands is small, but the total effect is large, about $10 \%$ of the column atmospheric heating. Absorption lines of gases and absorption and scattering properties of aerosols and cloud particles are taken from the HITRAN-96 molecular absorption database (Rothman et al. 1998). The code has eight spectral bands in the ultraviolet and visible regions of the solar spectrum and three bands in the near-infrared region. The solar radiative transfer is calculated with the delta-Eddington and two-stream adding approximations.

Aerosol optical properties are specified as inputs to the scheme. As the CPTEC AGCM lacks prognostic aerosol amounts and size distributions, we introduced a basic climatology of background aerosols. At each grid point we chose from two aerosol loadings, namely continental and oceanic. The continental aerosol has a column optical depth of 0.22 , homogeneously distributed in the first $2 \mathrm{~km}$ of the atmosphere, and is chosen over all land points except those with permanent ice. The value of 0.22 is derived from recent satellite measurements taken over the continents (Yu et al. 2006). That value describes the average aerosol loading over the continents far from strong sources of aerosol emission such as biomass burning. Similarly, the oceanic aerosol has a column optical depth of 0.14 (Yu et al. 2006) and is chosen over ocean and sea ice. The spectral variations of the aerosol optical parameters follow the continental and oceanic aerosol types from (World Meteorological Organization 1986). This prescription has rough spatial and temporal resolutions but allows for first-order effects of aerosols to be considered.

Tarasova et al. (2006) did an offline validation of the new scheme using as reference a state-of-the-art LBL method. They showed that the accuracy of the CLIRAD-SW-M scheme is superior to that of previous schemes for both incident solar radiation and atmospheric absorption. For clear-sky atmospheres, CLIRADSW-M corrected completely the systematic error for the midlatitude summer standard atmosphere and re- duced it to the order of $1-2 \mathrm{~W} \mathrm{~m}^{-2}$ for the tropical atmosphere in clear-sky conditions. It was also shown that for cloudy atmospheres the systematic differences from the $\mathrm{LBL}$ results were reduced to $6-8 \mathrm{~W} \mathrm{~m}^{-2}$.

\section{Model experiment and data used for validation}

Global climatology is simulated by integrating the model for $10 \mathrm{yr}$, from January 1985 to December 1994. To gain greater sample diversity and statistical significance, an ensemble mode is used in which integrations start from four different days, between 13 and 16 November 1984 . To investigate the model sensitivity to the changes in the radiation, three sets of model integrations with the new shortwave scheme (hereinafter called NEW model) were carried out. In the first set of integrations, the NEW model is used including all features of the SW scheme described in the section $2 b$, that is, background aerosols scattering and absorption and water vapor continuum absorption (hereinafter called NEW model results). In the second set the background aerosols effect was removed (hereinafter called N-A results). In the third set both the aerosols and the water vapor continuum effects were removed (hereinafter called N-WA results). A set of model integrations with the operational shortwave scheme (hereinafter called OPE model results) is used as a control.

The model resolution used for these climatic simulations is T62 L28, corresponding to a triangular truncation of 62 waves in the horizontal and 28 levels in the vertical sigma coordinate, with time steps of $20 \mathrm{~min}$. The initial conditions are from the 1200 UTC daily analysis of NCEP-NCAR. A monthly climatology of soil moisture and temperature is interpolated to the initial condition time and adjusted during integration by $\mathrm{SSiB}$. Albedo is predicted by $\mathrm{SSiB}$ over the land and is a function of solar zenith angle over the ocean. Monthly observed sea surface temperature (SST) from version 2 of the National Oceanic and Atmospheric Administration (NOAA) optimum interpolation (OI. v2) SST dataset (Reynolds et al. 2002) is used as the boundary condition. Climatological aerosol optical properties were specified as inputs to the scheme, as described in the previous section.

To validate the new radiation scheme, the data from the National Aeronautics and Space Administration (NASA) World Climate Research Program/Global Energy and Water Cycle Experiment (WCRP/GEWEX) Surface Radiation Budget (SRB) project (information online at http://eosweb.larc.nasa.gov/PRODOCS/srb/ table_srb.html) were used as the reference. The dataset used is release 2 of the monthly shortwave radiative fields generated with the Pinker-Laszlo shortwave al- 
TABLE 1. The global average of solar radiation absorption $\left(\mathrm{W} \mathrm{m}^{-2}\right)$, cloud radiative forcing $\left(\mathrm{CRF}, \mathrm{W} \mathrm{m}^{-2}\right)$, and albedo $(0-1)$ are presented. Results for the OPE and NEW models, satellite-derived observations from the SRB datasets, and multimodel means and std devs from Wild (2005) and Wild et al. (2006) are shown for all-sky and clear-sky conditions. Results from the experiments with the NEW model without aerosols and the water vapor continuum (N-WA) and without aerosols (N-A) are also shown. TOA: at the top of the atmosphere; ATM: in the atmosphere; SFC: at the surface.

\begin{tabular}{|c|c|c|c|c|c|c|}
\hline & OPE & N-WA & $\mathrm{N}-\mathrm{A}$ & NEW & SRB & Wild \\
\hline \multicolumn{7}{|c|}{ All-sky absorption } \\
\hline TOA & 244 & 244 & 244 & 241 & 241 & $236 \pm 6.5$ \\
\hline ATM & 63 & 63 & 64 & 68 & 74 & $74 \pm 7.3$ \\
\hline SFC & 181 & 181 & 180 & 173 & 167 & $162 \pm 8.4$ \\
\hline \multicolumn{7}{|c|}{ Clear-sky absorption } \\
\hline TOA & 298 & 296 & 297 & 291 & 288 & $290 \pm 3.9$ \\
\hline ATM & 63 & 64 & 68 & 72 & 70 & $67 \pm 4.6$ \\
\hline SFC & 236 & 232 & 229 & 219 & 218 & $222 \pm 6.8$ \\
\hline TOA SW CRF & -54 & -53 & -52 & -50 & -47 & $-54 \pm 1.7$ \\
\hline SFC albedo & 0.11 & 0.11 & 0.11 & 0.11 & 0.13 & $\mathrm{n} / \mathrm{a}$ \\
\hline TOA albedo & 0.31 & 0.31 & 0.30 & 0.31 & 0.32 & $0.31 \pm 0.01$ \\
\hline
\end{tabular}

gorithm (Pinker and Laszlo 1992), available from July 1983 to October 1995 . Quality control is accomplished by comparisons with a number of sites of the Baseline Surface Radiation Network (BSRN) over a period of 4 $\mathrm{yr}(1992-95)$. The mean bias is found to be $0.9 \mathrm{~W} \mathrm{~m}^{-2}$ (estimate - observation), and the random error is about $\pm 22.0 \mathrm{~W} \mathrm{~m}^{-2}$. For analyzing the cloud-radiative forcing, SRB longwave data are also used. The corresponding dataset is release 2.5 of the monthly longwave radiative fields derived with the GEWEX LW algorithm (Fu et al. 1997). Comparisons with BSRN found the mean bias to be about $-2.0 \mathrm{~W} \mathrm{~m}^{-2}$ (estimate observation), and the random error was about $\pm 13.3 \mathrm{~W}$ $\mathrm{m}^{-2}$. The NCEP-NCAR reanalysis (hereinafter called NCEP-R; Kalnay et al. 1996; Kistler et al. 2001) is used as a reference for comparing the model-simulated wind fields, temperature, and humidity. For evaluation of the impact of the new solar radiation scheme on global precipitation, the data from version 2 of the Global Precipitation Climatology Project (GPCP v2: Adler et al. 2003), as established by the World Climate Research Program (WCRP), available from 1979 to the present time were used.

\section{Results}

\section{a. Global energy balance}

The annual mean (1985-94) global average solar radiation absorbed at the top of the atmosphere (TOA), at the surface (SFC), and by the atmosphere (ATM) is shown in Table 1. The OPE and NEW model results appear in the first and fourth columns, respectively. The results from the N-WA runs (without aerosols and the water vapor continuum) and from the N-A runs (without aerosols) are shown in the second and third columns, respectively. The fifth column shows satellitederived observations from the SRB datasets. The sixth column shows the mean and standard deviation from all models participating in AMIP (Wild 2005; Wild et al. 2006).

As compared with the operational model integration, the atmospheric absorption increases by $5 \mathrm{~W} \mathrm{~m}^{-2}$ while the absorption at the surface decreases by $8 \mathrm{~W} \mathrm{~m}^{-2}$ in the new model integration. The net effect is a reduction of $3 \mathrm{~W} \mathrm{~m}^{-2}$ in the net shortwave absorbed by the earth, bringing the model's result into agreement with the observations. The largest change in atmospheric absorption $\left(4 \mathrm{~W} \mathrm{~m}^{-2}\right)$ is between N-A and NEW, showing that accounting for scattering and absorption of background aerosols is more important than for water vapor continuum absorption or the gaseous absorption. However, the clear-sky absorption values over ocean and land (see Table 2) indicate that the difference between the model results and satellite-derived estimates are probably related to the simple aerosol climatology used in the study. The aerosol loading seems to be overestimated over oceans and underestimated over land.

Disregarding the effects of clouds, the N-WA, N-A, and NEW atmospheres absorb 2,6 , and $10 \mathrm{~W} \mathrm{~m}^{-2}$ more than the OPE model atmosphere. At the same time, the radiation absorbed at the surface is lower by $-4,-7$, and $-17 \mathrm{~W} \mathrm{~m}^{-2}$, respectively. The differences between the clear-sky and all-sky results show an underestimation of the clouds' contribution to the atmospheric absorption. In fact, the model has less atmospheric absorption in cloudy-sky than in clear-sky conditions, while the satellite-derived results show the opposite effect. Results shown in Table 2 demonstrate that this happens over ocean and land, and for both OPE and NEW models. Over the oceans, there is a $+4 \mathrm{~W} \mathrm{~m}^{-2}$ 
TABLE 2. As in Table 1, but for occan and land separately.

\begin{tabular}{|c|c|c|c|c|c|c|c|c|c|c|}
\hline & \multicolumn{5}{|c|}{ Ocean } & \multicolumn{5}{|c|}{ Land } \\
\hline & OPE & N-WA & $\mathrm{N}-\mathrm{A}$ & NEW & SRB & OPE & N-WA & $\mathrm{N}-\mathrm{A}$ & NEW & SRB \\
\hline \multicolumn{11}{|c|}{ All-sky absorption } \\
\hline TOA & 254 & 254 & 255 & 251 & 251 & 218 & 218 & 219 & 216 & 216 \\
\hline ATM & 64 & 64 & 66 & 67 & 73 & 57 & 57 & 60 & 70 & 78 \\
\hline SFC & 190 & 190 & 189 & 184 & 179 & 161 & 161 & 159 & 146 & 138 \\
\hline \multicolumn{11}{|c|}{ Clear-sky absorption } \\
\hline TOA & 315 & 313 & 313 & 307 & 303 & 256 & 255 & 256 & 252 & 251 \\
\hline ATM & 64 & 66 & 70 & 71 & 67 & 57 & 59 & 62 & 75 & 78 \\
\hline SFC & 251 & 247 & 243 & 236 & 236 & 199 & 196 & 194 & 177 & 173 \\
\hline TOA SW CRF & -61 & -59 & -58 & -56 & -52 & -38 & -38 & -38 & -36 & -36 \\
\hline SFC albedo & 0.06 & 0.06 & 0.06 & 0.06 & 0.09 & 0.25 & 0.25 & 0.25 & 0.25 & 0.23 \\
\hline TOA albedo & 0.29 & 0.29 & 0.28 & 0.30 & 0.30 & 0.36 & 0.36 & 0.35 & 0.36 & 0.36 \\
\hline
\end{tabular}

bias in clear-sky atmospheric absorption and a $-5 \mathrm{~W}$ $\mathrm{m}^{-2}$ bias in cloudy-sky absorption. Over land, the biases in clear sky and cloudy sky are -3 and $-8 \mathrm{~W} \mathrm{~m}^{-2}$, respectively.

However, despite the model's deficiencies in the cloud parameterization, the changes in the shortwave scheme improve the average shortwave cloud radiative forcing (CRF). Moreover, Tables 1 and 2 clearly show that the NEW model fluxes are more accurate than the OPE model fluxes, for both clear-sky and all-sky conditions. This is due to the use of an updated water vapor absorption parameterization and the inclusion of absorption by weak water vapor lines, the water vapor continuum, $\mathrm{O}_{2}, \mathrm{CO}_{2}$, and aerosols.

\section{b. Heating and temperature}

Figure 1 shows the zonal mean atmospheric absorption for the OPE, N-WA, N-A, and NEW model results as well as for the satellite-derived observations. The differences between the model results and observations are more pronounced in the summer hemisphere. From the clear-sky results shown in Figs. 1a and 1b, one can see that the main impact comes from considering the scattering and absorption of background aerosols, particularly south of $60^{\circ} \mathrm{S}$ during DJF and between $5^{\circ}$ and $45^{\circ} \mathrm{N}$ during June-August (JJA). The absorption due to the water vapor continuum is the second most important contribution, mainly over the equatorial, tropical, and subtropical regions. The changes in the gaseous absorption are the least important factor and their impact increases poleward of the summer hemisphere.

The all-sky atmospheric absorption is presented in Figs. 1c and 1d. One can see that the model does not accurately account for the clouds' effects on atmospheric absorption in the equatorial and summer tropical regions. Yet, the model results are substantially im- proved in the integration with the NEW model. The only exception is the region around $60^{\circ}$. Moreover, the agreement between the model results and the observations poleward of $15^{\circ}$ of the winter hemisphere is within $1-2 \mathrm{~W} \mathrm{~m}^{-2}$ in this case.

Figure 2 shows the impact of the extra atmospheric absorption in the vertical heating of the atmosphere. Note that below $750 \mathrm{hPa}$ there is a systematic increase in the heating rates. The difference between the NEW and OPE models grows northward of $60^{\circ} \mathrm{S}$. It is $0 \%$ $15 \%$ between $60^{\circ}$ and $40^{\circ} \mathrm{S}, 15 \%-30 \%$ between $40^{\circ} \mathrm{S}$ and $20^{\circ} \mathrm{N}$, and $30 \%-60 \%$ north of $20^{\circ} \mathrm{N}$. The high values of the heating rate difference from the surface to $750 \mathrm{hPa}$ are related to solar radiation absorption by the background aerosols located in the near-surface layer (new solar radiation scheme). The systematic increase of this difference northward is due to the large impact of the absorption by the continental aerosols included over the land points in the NEW model. Note that the oceanic aerosol type included over the ocean points is characterized by weak absorption of solar radiation. There is also a general increase in the heating rates above $300 \mathrm{hPa}$, which is related to the $10 \%-40 \%$ increase in the specific humidity in this region (figure not shown) and to the enhanced ozone absorption in the NEW model (which is based on HITRAN-96). However, the largest increase is found over Antarctica and some cooling is found in the middle troposphere, between 300 and $600 \mathrm{hPa}$.

The differences between the model and the NCEP-R temperatures are shown in Figs. $3 \mathrm{a}$ and $3 \mathrm{~b}$. The OPE model shows a cooling bias all year round in the troposphere south of $40^{\circ} \mathrm{S}$ and in the upper troposphere north of $40^{\circ} \mathrm{N}$. However, Figs. $3 \mathrm{c}$ and $3 \mathrm{~d}$ show a general warming of the atmosphere with the NEW model with the highest temperature increases in the summer polar troposphere (up to $3 \mathrm{~K}$ warmer around $200 \mathrm{hPa}$ ) and in 

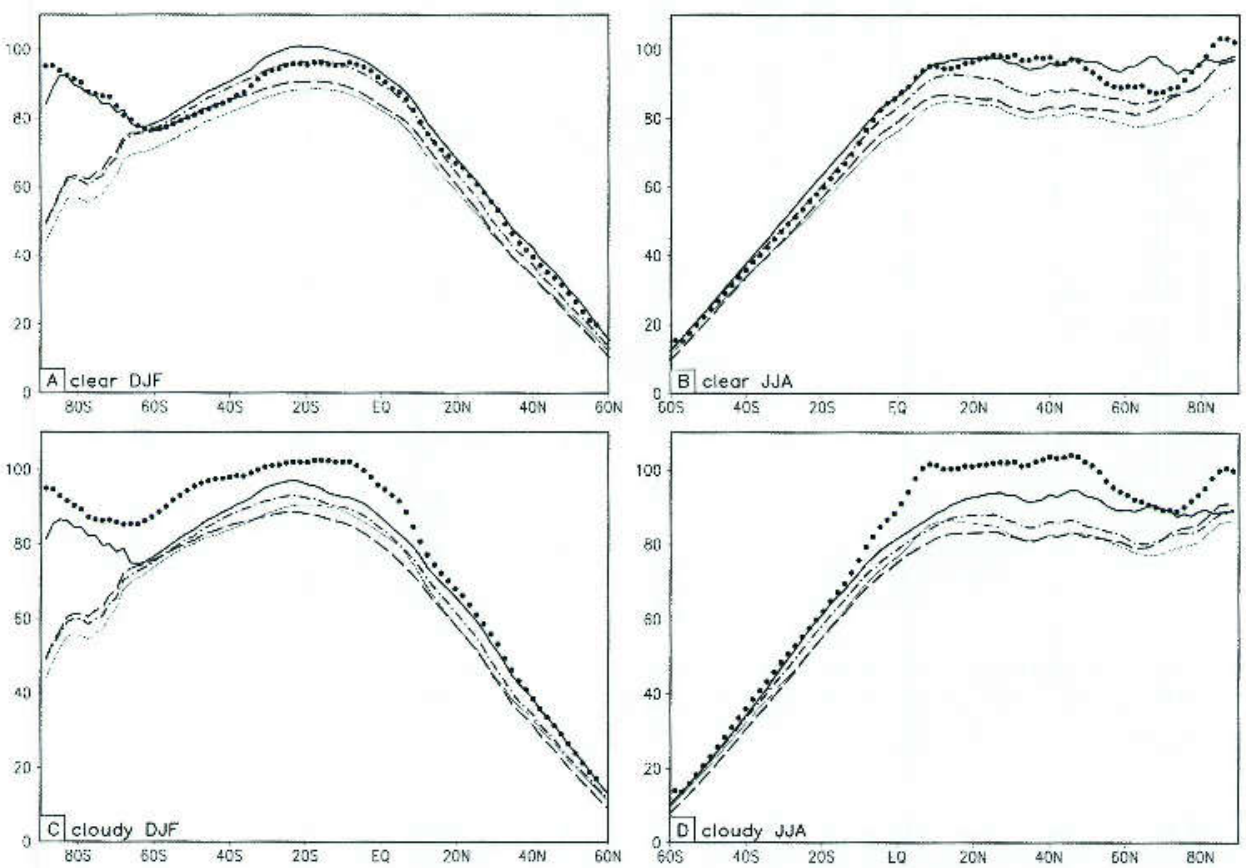

FIG. 1. Zonal mean atmospheric absorption $\left(\mathrm{W} \mathrm{m}^{-2}\right.$ ) averaged over (a) DJF and (b) JJA. Data from satellite-derived observations (SRB, circle) and the models OPE (thin line), N-WA (long dash), N-A (dot-dash), and NEW (thick line) are shown.

the stratosphere (up to $5 \mathrm{~K}$ warmer). A temperature decrease of less than $1 \mathrm{~K}$ is observed in some regions up to $300 \mathrm{hPa}$. This happens over the tropics and near the North Pole during DJF, and north of $40^{\circ}$ S during JJA. Thus, the CLIRAD-SW-M scheme helps to decrease the OPE model temperature bias. Furthermore, the higher temperature in the upper troposphere increases its static stability and will certainly lead to changes in the atmospheric circulation.

\section{c. Atmospheric circulation}

Figures $4 \mathrm{a}$ and $4 \mathrm{~b}$ show the zonal mean of the zonal wind for the NEW model. The general characteristics, such as the upper-level subtropical jets and the tropical easterly winds, are well captured. However, as noted by Cavalcanti et al. (2002, see Fig. 2 therein), the jet intensity in the CPTEC-COLA model is too high. Figures $4 \mathrm{c}$ and $4 \mathrm{~d}$ show the differences between the NEW and OPE model mean zonal winds. Both Northern and Southern Hemisphere jets are weakened, more significantly during DJF. This weakening comes from the warming produced near the poles, shown in Fig. 3, and the consequent reduction of the meridional temperature gradient (Souza et al. 1997). During DJF, tropical easterlies are weakened, reducing model bias, due to the cooling in the middle-troposphere equatorial region, shown in Fig. 3.
The zonal mean vertical circulation is shown in Fig. 5. During DJF, the upward branch of the Hadley cell is located at approximately $15^{\circ} \mathrm{S}$ and $5^{\circ} \mathrm{N}$, as in NCEP-R, but the intensity is overestimated below $600 \mathrm{hPa}$. These latitudes correspond to the more convective areas dur-

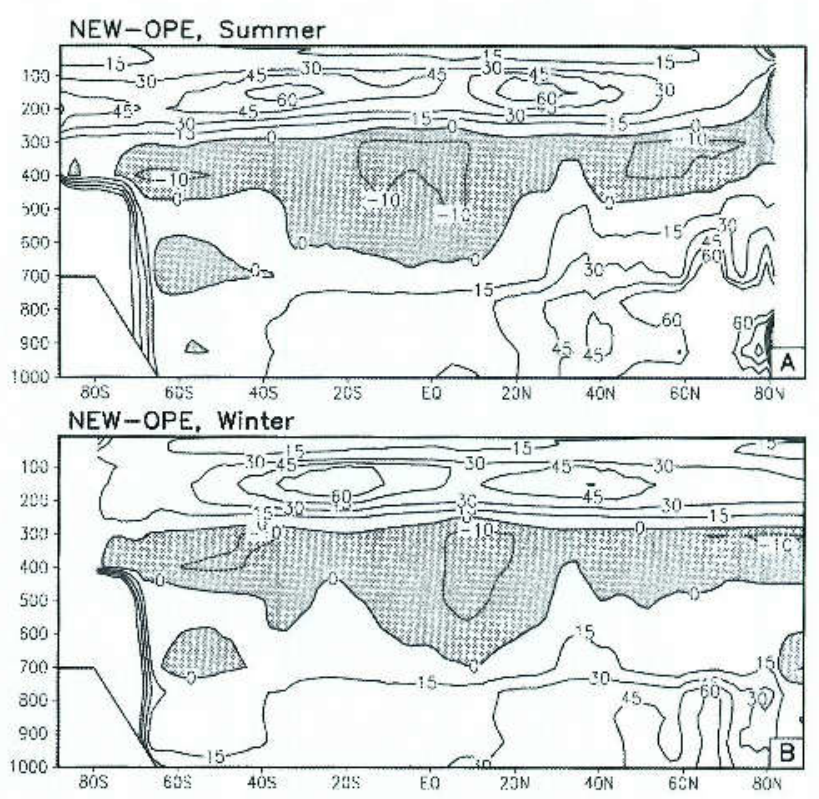

FIG. 2. Zonal mean shortwave heating rate difference (\%) between the NEW and OPE models during (a) DJF and (b) JJA. Negative values are shaded in gray. 

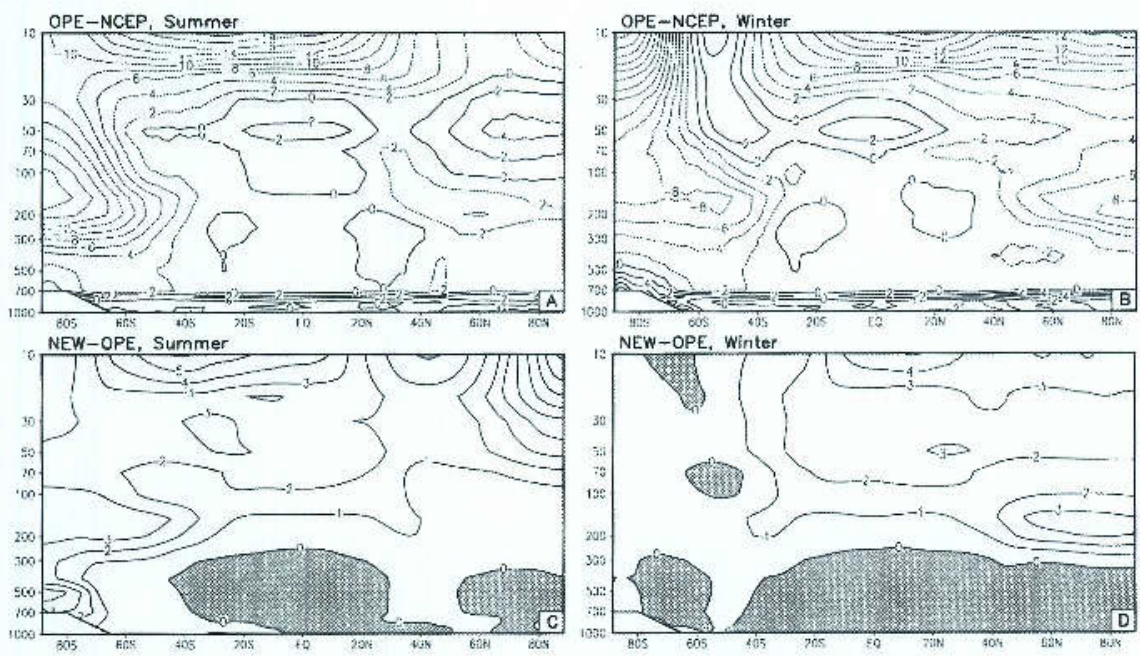

FIG. 3. Differences in zonal mean air temperature $\left({ }^{\circ} \mathrm{C}\right)$ between (a), (b) the OPE model and NCEP-R and (c), (d) the NEW and OPE models, during (left) DJF and (right) JJA. Negative values are shaded in gray.

ing this time of year, such as the Indian Ocean, the northern part of the South Pacific convergence zone (SPCZ), the north-west part of the South Atlantic convergence zone (SACZ), and the intertropical convergence zone (ITCZ), where the Kuo convection scheme is known to produce excessive precipitation (Cavalcanti et al. 2002). During DJF, the Ferrel cells are stronger in the model than in the reanalysis, mainly in the Southern Hemisphere. During JJA, the ascent branch of the Hadley cell is positioned around $10^{\circ} \mathrm{N}$ and is slightly more intense than in the reanalysis, but the subsidence branch is well described.

The NEW model has a weaker meridional circula- tion, but this is more evident in the Hadley cell and in the southern polar cell, during both DJF and JJA. Some weakening is also found in the Ferrel cell in the Southern Hemisphere. The reduction of the meridional flow intensity is due to the increase of the atmospheric stability observed in Fig. 3 and allows for a reduction in the moist convective forcing. These changes related to the extra atmospheric absorption of the NEW model helped in bringing the model closer to the observations.

\section{d. Surface fluxes}

The biases in the clear-sky solar radiation surface fluxes simulated by the NEW and OPE models are
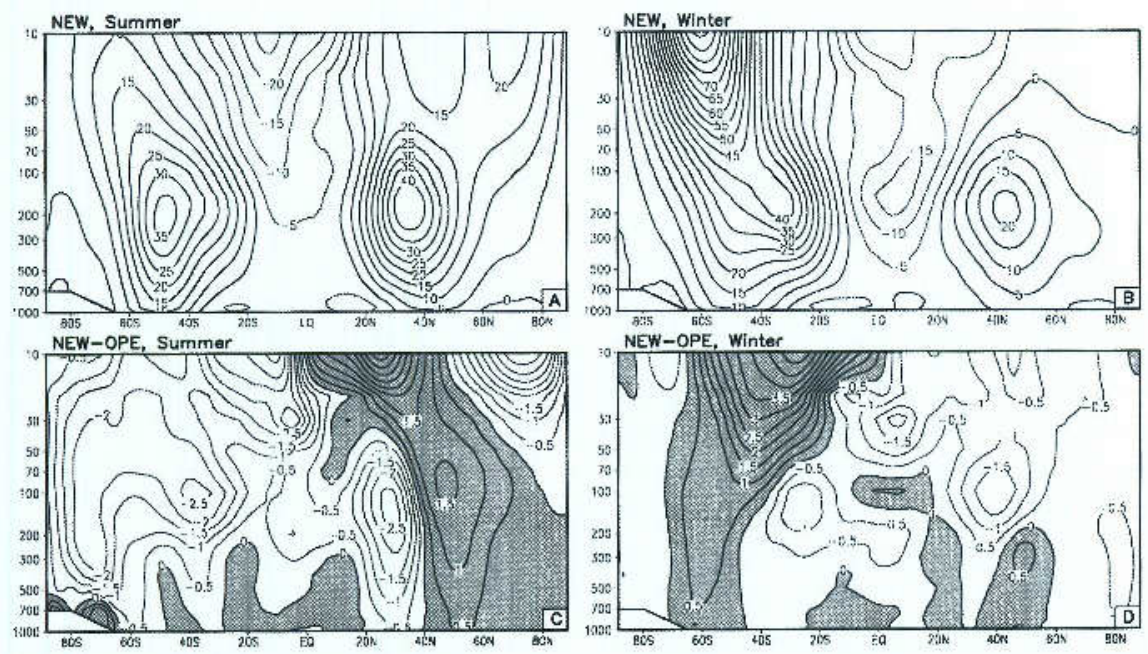

FIG. 4. Climatological vertical structure of zonal wind $\left(\mathrm{m} \mathrm{s}^{-1}\right)$ for the NEW model during (a) DJF and (b) JJA. Differences between the NEW and OPE models in (c) DJF and (d) JJA. Positive values are shaded in gray. 

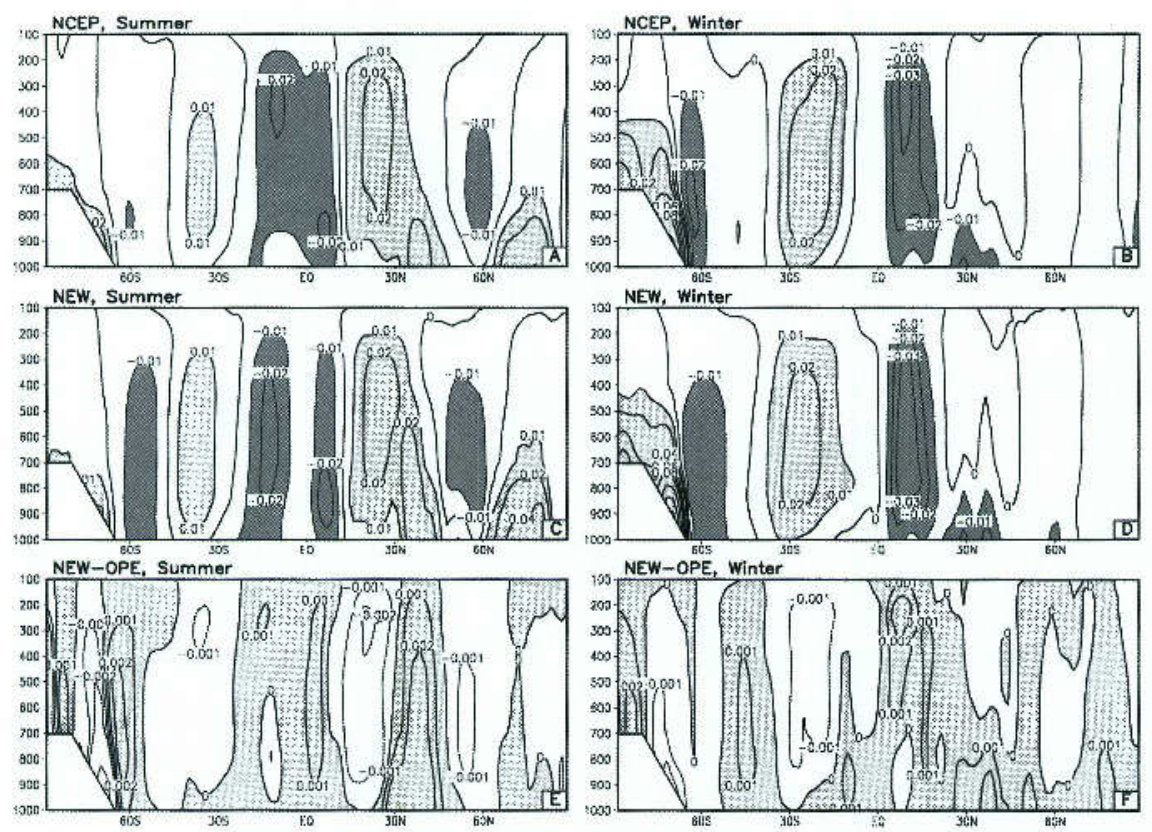

FIG. 5. Zonal mean vertical $p$ velocity $\left(\mathrm{Pa} \mathrm{s}^{-1}\right.$ ) for (a), (b) NCEP-R and (c), (d) the NEW model, during (left) DJF and (right) JJA. (e), (f) The differences between the NEW and OPE models, where positive $p$-velocity differences are shaded in gray.

shown in Fig. 6, as differences between model results and SRB estimates. The biases over continents are substantially reduced from $40-60$ to $10-20 \mathrm{~W} \mathrm{~m}^{-2}$. Over the oceans, however, the biases change from +12 to -7 $\mathrm{W} \mathrm{m^{-2 }}$ (see also Table 1). This indicates that the climatological value of the aerosol loading considered over the ocean (continent) is too high (too low) when compared with the values used for deriving the SRB clear-sky fluxes.

Figure $7 \mathrm{a}$ shows the difference between the NEW model and the observations in the all-sky flux at the surface. Comparisons with the results from the OPE model (not shown) show that the bias is reduced, while the spatial distribution of the differences remains the same. There is a high spatial correlation between these differences and the differences in cloud cover fraction, as can be seen by comparing Figs. $7 \mathrm{a}$ and $7 \mathrm{~b}$. Notice, for instance, the region of the Atlantic Ocean close to the eastern coast of Brazil, the SPCZ region, or the Southern Hemisphere midlatitudes.

The difference between the OPE model and the NCEP-R sensible heat fluxes at the surface is shown in Fig. 8a. Notice that the largest biases are seen over continental regions, particularly over South and North America. Figure $8 \mathrm{~b}$ shows that the NEW model reduces the bias and produces a general decrease in the sensible heat transfer at the surface and therefore is likely to decrease the boundary layer turbulence. The reduction over the oceans, which have a prescribed surface tem- perature, must come from the less intense low-level circulation alone (see Figs. $4 \mathrm{a}$ and $4 \mathrm{c}$ ). The reduction over the continental regions, however, stems also from the large reduction in the solar radiation incident at the surface.

Figure 9a shows the difference in the latent heat flux at the surface between the OPE model and NCEP-R.
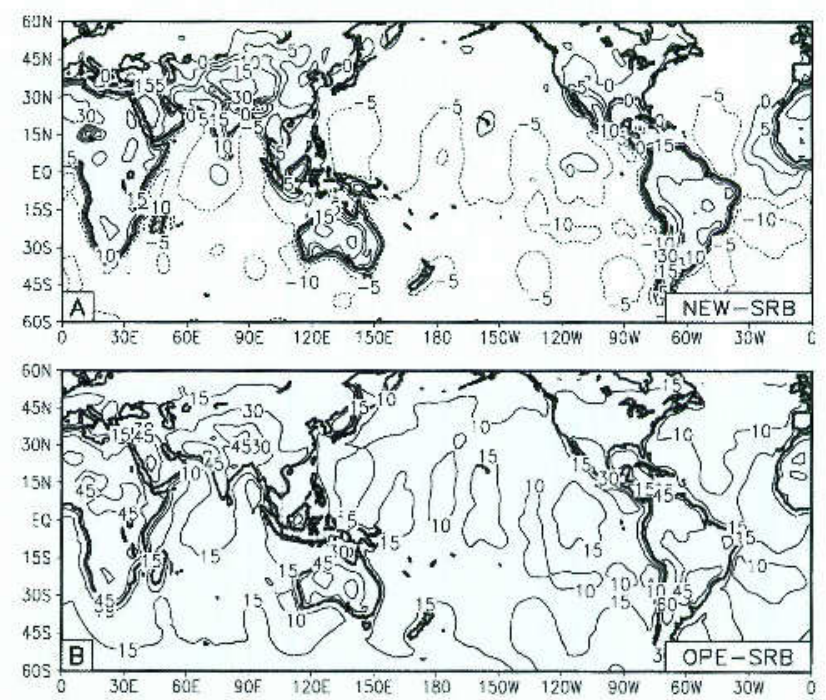

FIG. 6. Differences betwcen the (a) NEW and (b) OPE models and satellite-derived (SRB) estimations of DJF clear-sky shortwave radiation fluxes at the surface $\left(\mathrm{W} \mathrm{m}^{-2}\right)$. Regions with a positive bias are shaded in gray. 

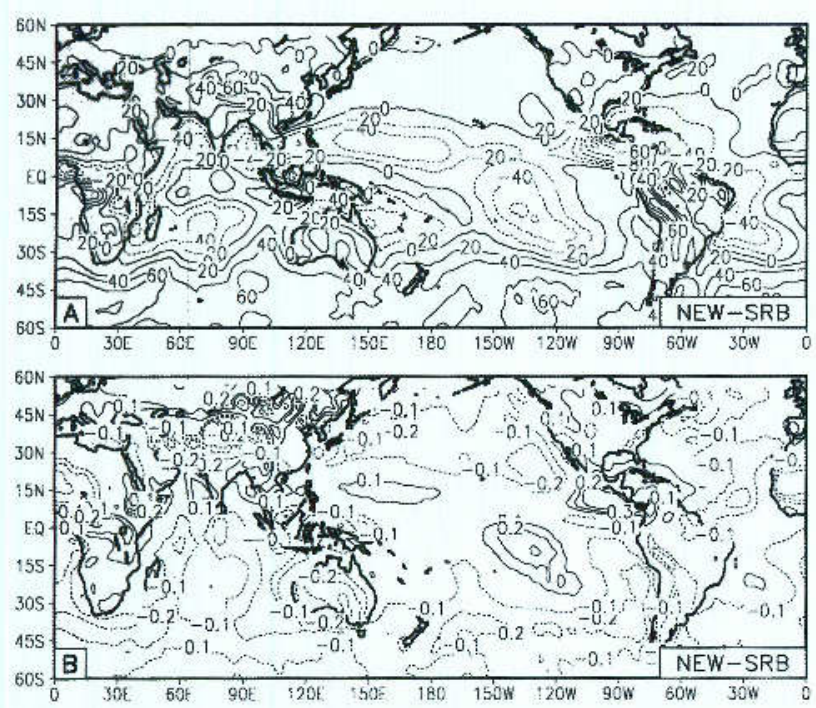

FIG. 7. Differences between the NEW model and satcllitederived (SRB) estimations of (a) all-sky shortwave flux at the surface $\left(\mathrm{W} \mathrm{m}^{-2}\right)$ and (b) total cloud cover during DJF. The spatial correlation coefficient between (a) and (b) is -0.66 , and regions with a positive flux bias are shaded in gray.

The largest differences are found where deep convection develops. For instance, over the SPCZ, the Atlantic ITCZ, and the NH storm tracks the difference reaches $80 \mathrm{~W} \mathrm{~m}^{-2}$. Figure $9 \mathrm{~b}$ shows that there is a decrease of the latent heat flux exactly over these regions, except for in the Atlantic ITCZ and South America. However, the spatial distribution of the differences was not changed with the new model (figure not shown).

\section{e. Cloud radiative forcing}

It is important to note that errors in cloud optical depth and/or cloud-top altitudes can also contribute to the errors in the all-sky flux at the surface. To further investigate this issue, we analyzed the cloud radiative forcing (CRF) in the same way as in Potter and Cess (2004). The SW and LW cloud radiative forcings (Ramanathan et al. 1989; Harrison et al. 1990) are defined as the difference between the clear-sky and all-sky outgoing fluxes at the top of the atmosphere:

$$
\begin{aligned}
& \mathrm{SWCRF}=\mathrm{SW} F_{\mathrm{TOA}}^{\uparrow_{c}}-\mathrm{SW} F_{\mathrm{TOA}}^{\uparrow} \text { and } \\
& \mathrm{LWCRF}=\mathrm{LW} F_{\mathrm{TOA}}^{\uparrow_{c}}-\mathrm{LW} F_{\mathrm{TOA}}^{\uparrow} .
\end{aligned}
$$

Then, the net cloud radiative forcing (netCRF) is given by netCRF $=$ SWCRF + LWCRF, and for regions where there is a balance between SWCRF and LWCRF, netCRF $\sim 0$ and the ratio $N=-\mathrm{SWCRF} /$ LWCRF $\sim 1$. In Fig. 10a, we show the observed netCRF. The difference between the NEW model and the SRB netCRF is shown in Fig. 10b. There is no signifi-
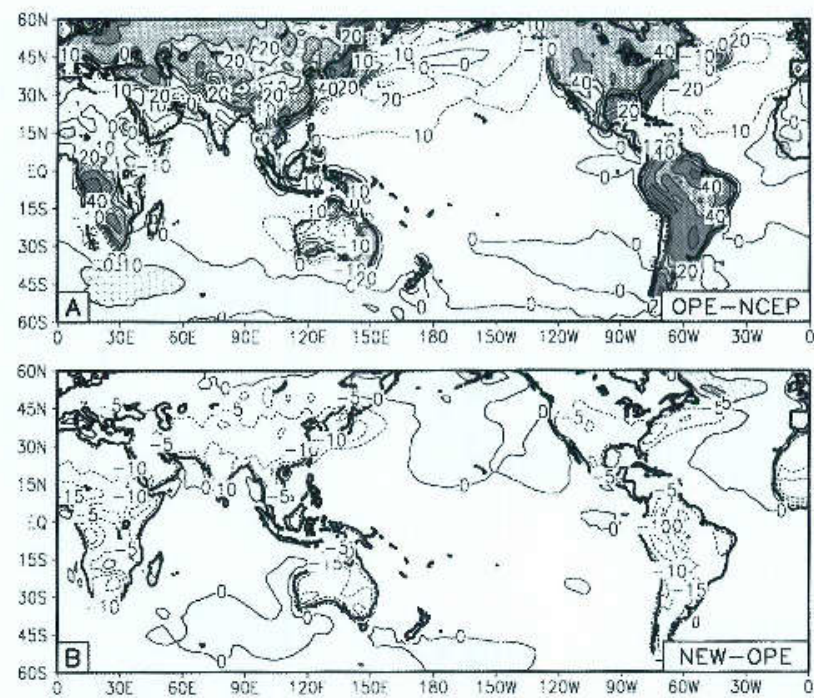

FIG. 8. Differences between (a) the OPE model and NCEP-R, and (b) the NEW and OPE estimations of surface sensible heat flux $\left(\mathrm{W} \mathrm{m} \mathrm{m}^{-2}\right.$ ) during DJF. Regions with a positive flux bias are shaded in gray.

cant improvement from the OPE model results (analysis not shown). This result was expected since both versions of the CPTEC AGCM use the same longwave, cloud, and convection parameterizations (see section 2).

For a detailed analysis of the radiative forcing, the region marked in Fig. 10b was chosen, where the model shows reasonable agreement with the observed netCRF. This region in the tropical western Pacific $\left(10^{\circ} \mathrm{N}-\right.$ $5^{\circ} \mathrm{S}$ and $117.5^{\circ}-170^{\circ} \mathrm{E}$ ) is dominated by deep convection, and therefore the netCRF $\sim 0$ and $\mathrm{N} \sim 1$ (Potter
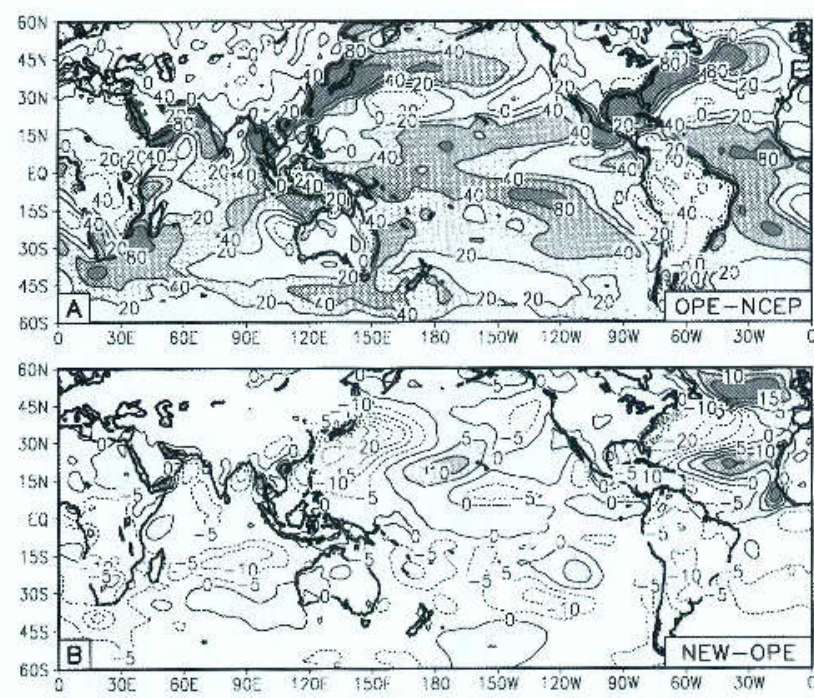

FIG. 9. Differences between (a) OPE and NCEP-R and (b) the NEW and OPE estimations of surface latent heat flux $\left(\mathrm{W} \mathrm{m}^{-2}\right)$ during DJF. Regions with a positive flux bias are shaded in gray. 

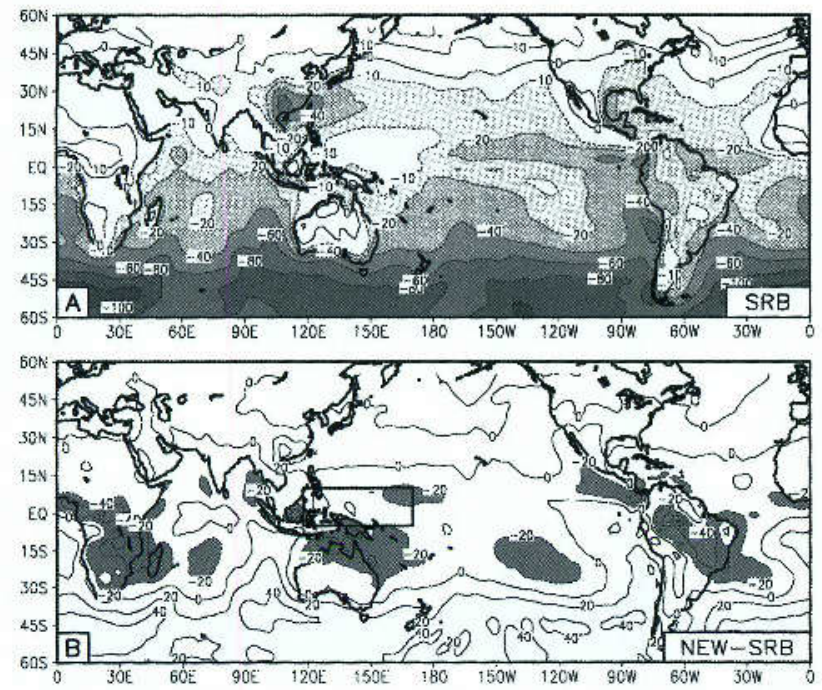

FIG. 10. Net cloud radiative forcing $\left(\mathrm{W} \mathrm{m}^{-2}\right)$ from (a) satellitederived observations (SRB) and (b) differences between the NEW model and the SRB observations during DJF. The region in the western tropical Pacific referenced in the text is also shown.

and Cess 2004). Figure 11 presents a scatterplot of $\mathrm{N} \times$ netCRF for the average SRB netCRF shown in Fig. 10 and the simulations with the NEW model. Each point on the plot corresponds to a grid box within the selected region. Because this plot is based on the average DJF distributions of SW and LW cloud radiative forcing, the points represent time averages of cloud systems and not specific cloud systems.

In this region, the NEW model produces overly bright clouds (spread in the upper-left corner) and little thin cirrus (lower right). The area average results in a negative netCRF bias of $-11 \mathrm{~W} \mathrm{~m}^{-2}$. The failure to simulate the observed CRF at TOA and all-sky shortwave at the surface is a consequence of errors in the vertical and spatial distributions of cloud cover and cloud optical depth. Moreover, these errors are intrinsically related to the model deficiencies in the convection parameterization because tropical convergence depends on the energy fluxes into the atmospheric column (Neelin and Held 1987). Figure 12 shows a scatterplot of convective precipitation versus SWCRF over the deep convective regions in the tropical oceans (annual mean SST $>27^{\circ} \mathrm{C}$ and $20^{\circ} \mathrm{S}-20^{\circ} \mathrm{N}$ ). Observed and model-simulated SWCRF values decrease roughly linearly with increasing precipitation, but the data seem to be offset. A closer look reveals that the model fails to produce low convective rainfall $\left(<2 \mathrm{~mm} \mathrm{day}^{-1}\right)$ and overestimates high convective rainfall $\left(>10 \mathrm{~mm}\right.$ day $\left.^{-1}\right)$. In fact, since SWCRF is overestimated and LWCRF agrees well with the observations (not shown), the netCRF (which should not vary with precipitation) de-

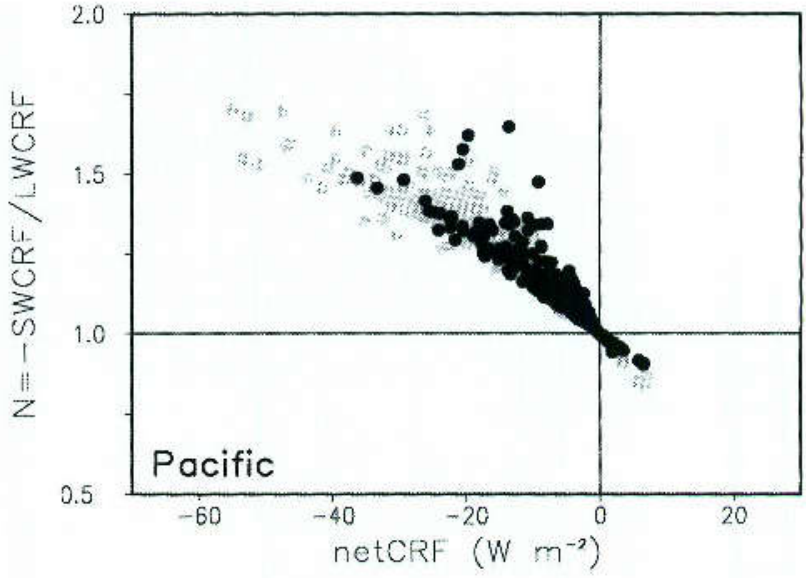

FIG. 11. Scatterplot of $N \times$ netCRF from SRB satellite-derived observations (black) and the NEW model (gray) for DJF. Each point corresponds to a grid point over the tropical western Pacific region $\left(10^{\circ} \mathrm{N}-5^{\circ} \mathrm{S}\right.$ and $\left.117.5^{\circ}-170^{\circ} \mathrm{E}\right)$.

creases with increasing precipitation by $7 \mathrm{~W} \mathrm{~m}^{-2}$ per $\mathrm{mm} \mathrm{day}^{-1}$. This means the model is holding less radiative energy as convection increases.

\section{f. Precipitation}

As mentioned by Cavalcanti et al. (2002), the model overestimates the precipitation over parts of South America, the South Pacific, and the ITCZ. However, with the improvement in the shortwave radiation scheme, some of the systematic errors were diminished. Figure 13 shows, for each model run, the difference in the global mean precipitation of the OPE model ensemble mean. Notice that the average reduction in precipitation is statistically significant, even though the ab-

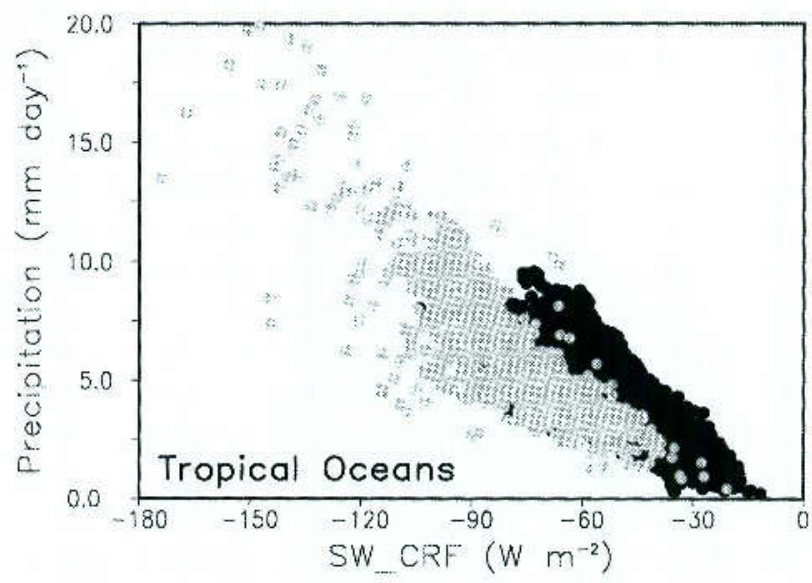

FIG. 12. Scatterplot of the convective precipitation vs SWCRF over the tropical oceans $\left(20^{\circ} \mathrm{S}-20^{\circ} \mathrm{N}\right)$ with annual mean SST $>$ $27^{\circ} \mathrm{C}$. Observations from SRB and GPCP (black) and the NEW model (gray) annual means are shown. 


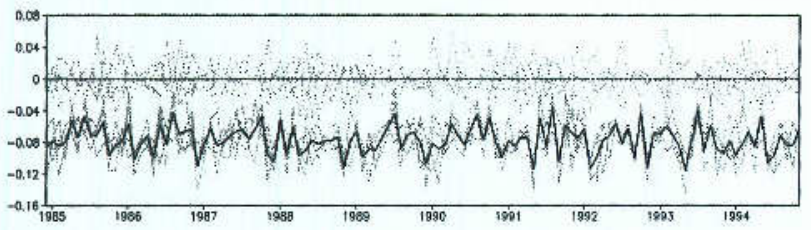

FIG. 13. Global mean precipitation difference between individual model runs and the ensemble of the OPE model runs ( $\mathrm{mm}$ day ${ }^{-1}$ ). Integrations with the OPE and NEW models are drawn as dotted and full gray lines, respectively. The ensemble means are drawn as thick black lines.

solute value of $0.08 \mathrm{~mm}^{\text {day }}{ }^{-1}(3 \%)$ is small when compared with the total precipitation.

These changes in precipitation have a large spatial variation and most of the reduction is found over the oceans, as shown in Fig. 14. Comparing with the results of Cavalcanti et al. (2002), we see that the new radiation scheme helped to reduce the model bias over the SPCZ region by $0.5-1.0 \mathrm{~mm}^{-1 a y}{ }^{-1}$ and over the Northern Hemisphere storm tracks region by $0.5 \mathrm{~mm}$ day ${ }^{-1}$. Over South America, there was a reduction of 0.5-1 $\mathrm{mm}$ day $^{-1}$ in the model systematic error over some regions. However, these figures are smoothed by the 10 -yr time average. The changes in precipitation during each individual DJF period are larger by a factor of 5 approximately, as shown in Fig. 15. Over the SACZ, for instance, differences of $\pm 2-3 \mathrm{~mm}$ day $^{-1}(15 \%-25 \%)$ are found every year.

\section{Discussion}

As compared with the OPE model results, the $\mathrm{N}-\mathrm{WA}, \mathrm{N}-\mathrm{A}$, and NEW models show increases in atmospheric absorption (Table 1) of $0.1 \%, 1.5 \%$, and $7.9 \%$, respectively, for all-sky conditions, and $1.5 \%$, $7.9 \%$, and $14 \%$, respectively, for clear-sky conditions. These values show that the most important changes introduced with the NEW model are related first to the scattering and absorption by climatological aerosols and second to the absorption by the water vapor continuum. The satellite-derived data used as a reference, when compared to ground truth, have a mean bias of about $0.9 \mathrm{~W} \mathrm{~m}^{-2}$ and a random error of about $\pm 22.0 \mathrm{~W}$ $\mathrm{m}^{-2}$. This means that the remaining $+2 \mathrm{~W} \mathrm{~m}^{-2}$ bias in the clear-sky atmospheric absorption with the NEW model is within the precision of the SRB satellite estimates. Note that the current version of CLIRADSW-M is based on the HITRAN-96 molecular absorption database and uses version 2.1 of the CloughKneizys-Davies (CKD-2.1; Clough et al. 1989) parameterization of the water vapor continuum. The impact of different spectroscopic databases and ver-

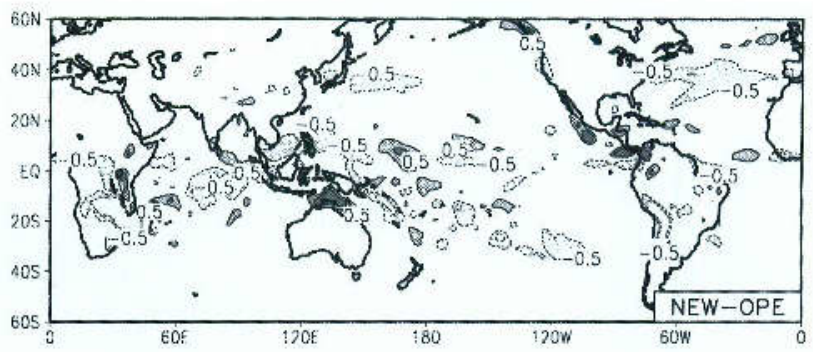

FIG. 14. The improvement in the D.JF precipitation distribution shown as the difference in DJF precipitation $\left(\mathrm{mm} \mathrm{day}^{-1}\right)$ between the NEW and OPE models.

sions of the water vapor continuum on the calculated solar radiative fluxes is discussed by Fomin et al. (2004). A flux difference of $1-3 \mathrm{~W} \mathrm{~m}^{-2}$ is found that is due to the change of the HITRAN-96 database with the CKD2.1 continuum to the HITRAN-2001 database with the CKD-2.4 continuum in the line-by-line calculations. This flux difference, which is mainly related to the change of the continuum version, can affect the model results. Moreover, Fig. 6 shows a clear difference between the remaining bias in the surface flux over the continents and oceans, which indicates that climatological values of aerosol loading considered over the ocean (continent) were too high (low) when compared with the values used for deriving the SRB clear-sky fluxes.

Figure 7 shows the largest impact of the new scheme on the surface shortwave fluxes to be exactly over the regions where the largest model biases were found. There are still large differences from the observations in the all-sky surface flux (from -40 to $+60 \mathrm{~W} \mathrm{~m}^{-2}$ in the tropical and subtropical regions), which we show to be related to the deficiencies in the model cloud parameterization (cf. Figs. 10b and 7a). The cloud-radiative forcing analysis shows similar deficiencies in both the OPE and NEW models, which was expected as both use the same longwave and cloud parameterizations. Over the Pacific ITCZ, the OPE and NEW CPTEC models, like the original COLA model (Fig. 6 in Potter and Cess 2004), produce overly bright clouds and little thin cirrus, which results in a negative bias in the shortwave flux at the surface. It is interesting to compare the results from Potter and Cess (2004) obtained for the COLA model with our results with the NEW model, as both rely on the same cloud parameterization. Figure 11 in the previous section and Figs. 6 and 7 from Potter and Cess (2004) show that improvements implemented at CPTEC led to a significant improvement in the model CRF.

The extra radiative heating of the atmosphere (Fig. 2) led to significant changes in the temperatures of the polar summer troposphere (Fig. 3). However, the in- 

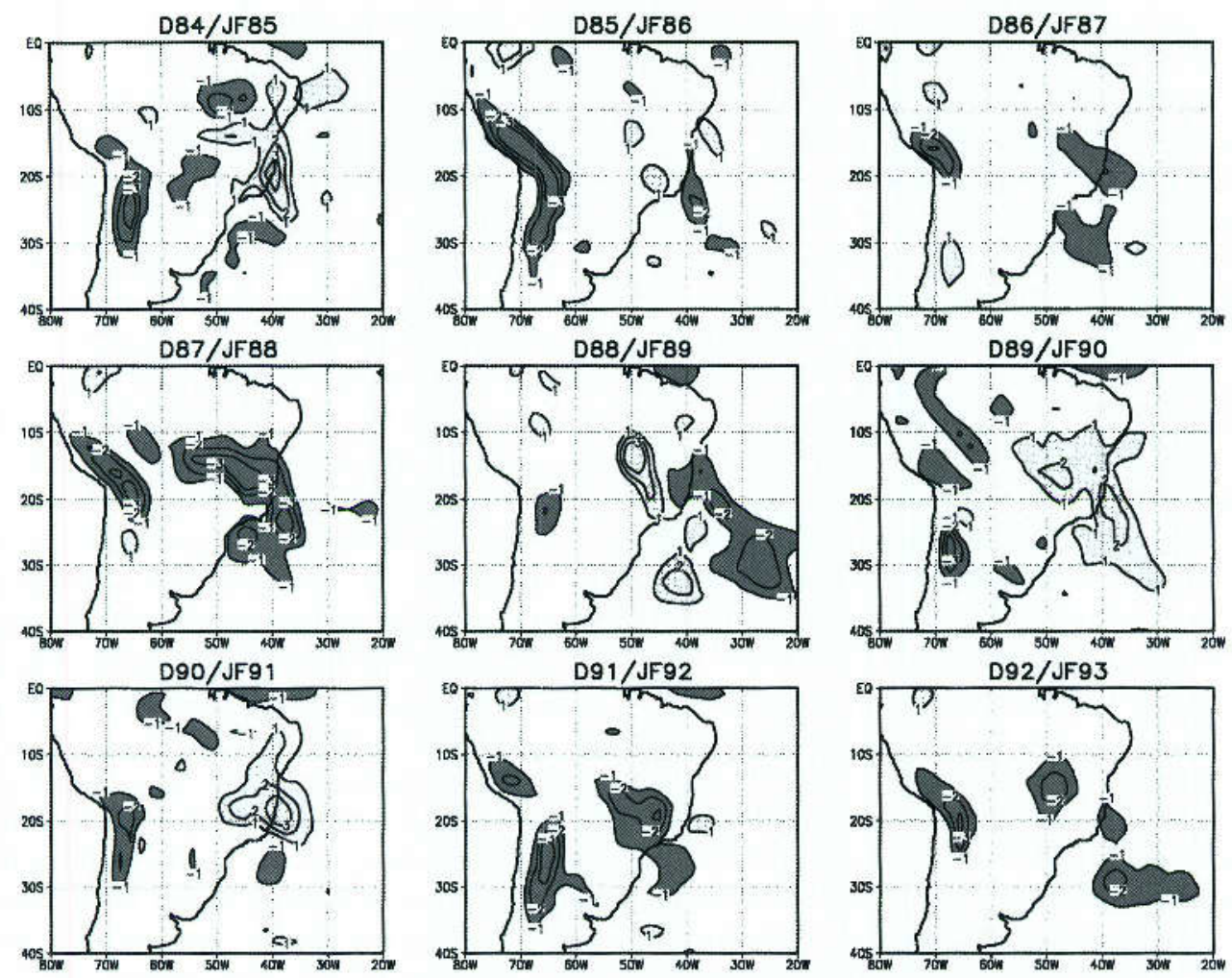

FIG. 15. Changes in the DJF precipitation distribution for the first nine DJF periods. The difference in DJF precipitation $\left(\mathrm{mm} \mathrm{day}^{-1}\right)$ between the NEW and OPE models is shown.

crease in the temperature, which was on the order of 3 $\mathrm{K}$, is not enough to correct the OPE model bias of about $-10 \mathrm{~K}$. In the stratosphere the changes were around $4 \mathrm{~K}$ and over the winter pole, they were more than $8 \mathrm{~K}$. These results agree with the previous results of Ramanathan et al. (1983) and Hart et al. (1990), who showed the equilibrium between the radiative and dynamic forcings in the stratosphere to be very sensitive to the parameterization of radiation. However, even with this increase in the stratospheric temperatures due to the extra atmospheric absorption of solar radiation, there is still a $-10 \mathrm{~K}$ bias. Results from Ramanathan et al. (1983) indicate that this might be related to the longwave scheme used. Ramanathan et al. (1983) estimated that if the scheme they used assumed a constant water vapor mixing ratio of $3 \mathrm{ppm}$ in the stratosphere (as in the NEW and OPE models), their simulations would have overestimated the cooling rates by about $0.1 \mathrm{~K}$ day $^{-1}$ and cooled the stratosphere by $10 \mathrm{~K}$.

With the reduced availability of energy at the surface, the sensible heat over the continents and the latent heat over the oceans were reduced, as shown in Figs. 8 and 9. This means a reduction of energy available for convection, which is in accordance with the weakening of the meridional circulation (Fig. 5) and the reduction of precipitation (Fig. 13). This is similar to the results of Morcrette (1990) for short-term integrations of the ECMWF model. He showed that a decrease in the bias of the atmospheric absorption of solar radiation from $+15 \% \sim 20 \%$ to less than $+5 \%$ led to a $15 \%$ stronger hydrological cycle and meridional circulation. In our study, the improved solar radiation scheme helped to reduce the negative bias from $-15 \%$ to $-7 \%$ (see Table 1 ) and slowed down the hydrological cycle by $3 \%$ on average. Considering South America only, the OPE model bias was reduced from +43 to $+23 \mathrm{~W} \mathrm{~m}^{-2}$ in the NEW model. The reduction of the precipitation over the ocean in the SACZ was only $-1 \mathrm{~mm} \mathrm{day}^{-1}(\sim 6 \%)$. However, these figures are smoothed by the $10-y r$ time average. When we analyze individually each DJF period, we find positive and negative differences of $\pm 2-3 \mathrm{~mm} \mathrm{day}^{-1}(15 \%-25 \%)$ which are slightly unbalanced. Our results indicate that significant impacts on the hydrological cycle are to be expected at monthly time scales but not at yearly time scales. This might be important for seasonal forecasting of temperature and precipitation anomalies, particularly when anomalies are calculated by differences between an ensemble of short forecast integrations and a multiyear model climatology. One should expect, how- 
ever, that the convection and surface parameterizations play an important role in determining the response of the hydrological cycle to changes in the radiation. In fact, preliminary results with the NEW model and the Grell deep convection scheme (Figueroa et al. 2006) have shown a larger response by the hydrological cycle at the decadal time scale and a great improvement in the model DJF precipitation spatial distribution.

\section{Summary}

We have shown that using the CLIRAD-SW-M scheme of the CPTEC GCM simulates fluxes and atmospheric absorption that are closer to the observations than are those provided by the operational model. The global yearly average underestimation of the atmospheric absorption decreased from -9 to $-6 \mathrm{~W} \mathrm{~m}^{-2}$, while overestimation of solar radiation at the surface decreased from +14 to $+6 \mathrm{~W} \mathrm{~m}^{-2}$. Comparisons with model runs without the background aerosols included in the radiation scheme showed that they are responsible for approximately $80 \%$ of this extra absorption, even though they respond only to $50 \%$ of the clear-sky extra absorption. Moreover, we have also shown that the agreement between the model and the observations under these conditions is now within $\pm 3 \mathrm{~W} \mathrm{~m}^{-2}$, which is well within the precision of the observed data.

The zonal average of the model atmospheric absorption has shown significant improvement in the model integrations with the CLIRAD-SW-M scheme. For both DJF and JJA, the biases over the winter hemisphere were completely corrected while over the summer hemisphere they were reduced to less than $-15 \mathrm{~W}$ $\mathrm{m}^{-2}$, with a large impact of the aerosol scattering and absorption near the poles and of the water vapor continuum absorption in the equatorial and tropical regions. The largest improvement was over Antarctica, where the bias was reduced from -45 to $-12 \mathrm{~W} \mathrm{~m}^{-2}$ during DJF. However, we found that there is still a bias in the surface fluxes, which is mainly due to model deficiencies related to cloud parameterization.

The extra atmospheric heating increased the tropospheric temperatures by $\sim 3 \mathrm{~K}$ and the stratospheric temperatures by $\sim 5 \mathrm{~K}$. In the polar night region, due to dynamic forcing, temperature changes of $\sim 8 \mathrm{~K}$ were found, which reduced the model temperature bias. These results agree with the previous results of $\mathrm{Ra}$ manathan et al. (1983) and Hart et al. (1990), who showed that the equilibrium between radiative and dynamic forcings in the stratosphere is very sensitive to the parameterization of radiation. However, there is still a cold bias of $-10 \mathrm{~K}$ in the polar stratosphere, which probably comes from the use of a constant $3 \mathrm{ppm}$ water vapor mixing ratio in this region (Ramanathan et al. 1983).

The increase in temperature in the upper troposphere and reduction of the temperature gradient between the poles and the equatorial region increased the static stability and reduced both the meridional and zonal circulations. The intensity of the tropospheric jets is reduced by $7 \%-8 \%$, while that of the polar night stratospheric jet was increased by $5 \%-10 \%$. The vertical velocities in the Hadley and southern polar cells were reduced by $20 \%\left(\sim 0.005 \mathrm{~Pa} \mathrm{~s}^{1}\right)$. Both results bring the model-simulated wind fields closer to the observed values.

It was also shown that the reduced availability of the latent energy for the saturated convective processes weakened the meridional circulation and slightly slowed down the hydrological cycle. The overestimation of the global yearly average of precipitation decreased from +0.8 to $+0.7 \mathrm{~mm} \mathrm{day}^{-1}$. The new radiation scheme helped to reduce the model bias over the SPCZ by $0.5-1.0 \mathrm{~mm} \mathrm{day}^{-1}$ and that over the Northern Hemisphere storm tracks region by $0.5 \mathrm{~mm} \mathrm{day}^{-1}$. On a monthly time scale, the impacts are stronger. Over the $\mathrm{SACZ}$ we found positive and negative differences of $\pm 2-3 \mathrm{~mm} \mathrm{day}^{-1}(15 \%-25 \%)$ during individual DJF periods.

This is potentially important for seasonal forecasting particularly when anomalies are calculated by differences between an ensemble of short forecast integrations and a multiyear model climatology, as is operationally performed by CPTEC. However, further investigation of this subject is necessary and will be done in a future study. Moreover, the convection and surface parameterizations probably play a more important role in determining the magnitude of the response of the hydrological cycle. In fact, the preliminary results of Figueroa et al. (2006) with the NEW model and the Grell deep convection scheme have shown a larger response from the hydrological cycle and significant improvement in the model precipitation.

We stress that the use of GCMs in operational seasonal forecasting or in climate change assessments requires that the model simulates well the present observed climate and its variability. In this sense, this study shows how a new shortwave radiation parameterization produced significant improvements in the CPTEC model's ability to represent observed characteristic features of the earth radiation budget, atmospheric circulation, and precipitation.

Acknowledgments. HMJB and TAT were supported by grants from NEC-NDB. IFAC is grateful to the Conselho Nacional de Desenvolvimento Cientifico e 
Tecnológico $(\mathrm{CNPq})$ for research funding. NCEPNCAR reanalysis data were obtained free of charge from the NCAR ds090.2 dataset (available online at http://dss.ucar.edu/pub/reanalysis/).

\section{REFERENCES}

Adler, R. F., and Coauthors, 2003: The version 2 Global Precipitation Climatology Project (GPCP) monthly precipitation analysis (1979-present). J. Hydrometeor, 4, 1147-1167.

Anthes, R. A., 1977: Hurricane model experiments with a new cumulus parameterization scheme. Mon. Wea. Rev., 105, 270286.

Briegleb, B. P., 1992: Delta-Eddington approximation for solar radiation in the NCAR Community Climate Model. $J$. Geophys. Res., 97, 7603-7612.

Cavalcanti, I. F. A., and Coauthors, 2002: Global climatological features in a simulation using the CPTEC-COLA AGCM. $J$. Climate, 15, 2965-2988.

Cess, R. D., and Coauthors, 1995: Absorption of solar radiation by clouds: Observations versus models. Science, 267, 496-499.

Chagas, J. C. S., P. Nobre, and M. Malagutti, 2004: Modifications on the CPTEC global model radiation scheme. Proc. $X I I I$ Brazilian Meteorology Conf., Fortaleza-Ceará, Brazil, Instituto Nacional de Pesquisa Espaciais (INPE), INPE Tech. Doc. INPE-12070-PRE/7416. [Available online at http:// urlib.net/cptec.inpe.br/walmeida/2004/09.27.11.05.]

Chou, M. D., and M. J. Suarez, 1999: A solar radiation parameterization (CLIRAD-SW) for atmospheric studies. NASA/TM1999-104606, M. J. Suarez, Ed., Series on Global Modeling and Data Assimilation, Vol. 15, 40 pp.

Clough, S. A., F. X. Kneizys, and R. W. Davies, 1989: Line shape and the water vapor continuum. Atmos. Res., 23, 229-241.

- , and Coauthors, 2005: Atmospheric radiative transfer modeling: A summary of AER codes. J. Quant. Spectrosc. Radiat. Transfer, 91, 233-244.

Collins, W. D., 2006: Unresolved issues in atmospheric solar absorption. Frontiers of Climate Modeling, J. T. Kiehl and V. Ramanathan, Eds., Cambridge University Press, 179-216.

- - J. M. Lee-Taylor, D. P. Edwards, and G. L. Francis, 2006: Effects of increased near-infrared absorption by water vapor on the climate system. J. Geophys. Res., 111, D18109, doi:10.1029/2005JD006796.

Cusack, S., A. Slingo, J. M. Edwards, and M. Wild, 1998: The radiative impact of a simple aerosol climatology on the Hadlcy Centre atmospheric GCM. Quart. J. Roy. Meteor. Soc., 124, 2517-2526.

Davies, R, 1982: Documentation of the solar radiation parameterization in the GLAS climate model. NASA Tech. Memo. $83961,57 \mathrm{pp}$. [Available from National Technical Information Service, 5285 Port Royal Rd., Springfield, VA 22161.]

Figueroa, S. N., T. Tarasova, H. M. J. Barbosa, J. P. Bonatti, and P. L. Silvia Dias, 2006: The impact of cumulus and radiation parameterization schemes on Southern Hemisphere summer climate simulated by CPTEC atmospheric general circulation model. Proc. Eighth Int. Conf. on Southern Hemisphere Meteorology and Oceanography, Foz do Iguaçu, Brazil, INPE, $1037-1040$.

Fomin, B., and Y. Gershanov, 1996: Short-Wave Results. Vol. II, Tables of the Benchmark Calculations of Atmospheric Fluxes for the ICRCCM Test Cases. Vol. IAE-5990/1, Kurchatov Institute, Moscow, Russia, 42 pp.
—, T. Udalova, and E. Zhitnitskii, 2004: Evolution of spectroscopic information over the last decade and its effect on lineby-line calculations for validation of radiation codes for climate models. J. Quant. Spectrosc. Radiat. Transfer, 86, 73-85.

Fu, Q., K. N. Liou, and M. C. Cribb, 1997: Multiple scattering parameterization in thermal infrared radiative transfer. $J$. Atmos. Sci., 54, 2799-2812.

Gates, W, 1992: AMIP: The Atmospheric Model Intercomparison Project. Bull. Amer. Meteor. Soc., 73, 1962-1970. , and Coauthors, 1999: An overview of the results of the Atmospheric Model Intercomparison Project (AMIP). Bull. Amer. Meteor. Soc., 80, 29-55.

Harrison, E. F., P. Minnis, B. R. Barkstrom, V. Ramanathan, R. D. Cess, and G. G. Gibson, 1990: Seasonal variation of cloud radiative forcing derived from the Earth Radiation Budget Experiment. J. Geophys. Res., 95, 18 687-18 703.

Harshvardhan, and T. G. Corsetti, 1984: Longwave radiation parameterization for the UCLA/GLAS GCM. NASA Tech. Memo. 86072, 65 pp.

- D. A. Randall, and T. G. Corsetti, 1987: A fast radiation parameterization for general circulation models. J. Geophys. Res., 92, 1009-1016.

Hart, T. L., and Coauthors, 1990: Atmospheric general circulation simulations with the BMRC Global Spectral Model: The impact of revised physical parameterizations. J. Climate, 3, 436459.

Hou, Y. T., 1990: Cloud-radiation dynamics interaction. Ph.D. thesis, University of Maryland, $209 \mathrm{pp}$.

Hurrell, J. W., J. J. Hack, B. A. Boville, D. L. Willianson, and J. T. Kiehl, 1998: The dynamical simulation of the NCAR Community Climate Model Version 3 (CCM3). J. Climate, 11, $1207-1236$.

Johns, T. C., R. E. Carnell, J. F. Crossley, J. M. Gregory, J. B. Mitchell, C. A. Senior, S. B. Tett, and R. A. Wood, 1997: The second Hadley Centre coupled ocean-atmosphere GCM: Model description, spinup and validation. Climate Dyn., 13, 103-134.

Kalnay, E, and Coauthors, 1996: The NCEP/NCAR 40-Year Reanalysis Project. Bull. Amer. Meteor. Soc., 77, 437-471.

Kiehl, J. T., 1994: Clouds and their effects on the climate system. Phys. Today, 47, 36-42.

- J. J. Hack, M. H. Zhang, and R. D. Cess, 1995: Sensitivity of a GCM climate to enhanced shortwave cloud absorption. $J$. Climate, 8, 2200-2212.

Kistler, R., and Coauthors, 2001: The NCEP-NCAR 50-Year Reanalysis: Monthly means CD-ROM and documentation. Bull. Amer. Meteor. Soc, 82, 247-267.

Kuo, H. L., 1974: Further studies of the parameterization of the influence of cumulus convection on large-scale flow. $J$. Atmos. Sci., 31, 1232-1240.

Lacis, A. A., and J. E. Hansen, 1974: A parameterization for the absorption of solar radiation in the earth's atmosphere. $J$. Atmos. Sci, 31, 118-133.

Li, Z., L. Moreau, and A. Arking, 1997: On solar energy disposition: A perspective from observation and modeling. Bull. Amer. Meteor. Soc., 78, 53-70.

Lohmann, U., and R. Bennartz, 2002: Impact of improved nearinfrared water vapor line data in simulations with the ECHAM4 general circulation model. J. Geophys. Res., 107, 4288, doi: $10.1029 / 2001$ JD001101.

Mellor, G. L., and T. Yamada, 1982: Development of a turbulence closure model for geophysical fluid problems. Rev. Geophys. Space Phys, 20, 851-875. 
Monin, A. S., 1986: An Introduction to the Theory of Climate. D. Reidel, $261 \mathrm{pp}$.

Morcrette, J.-J., 1990: Impact of changes to the radiation transfer parameterizations plus cloud optical properties in the ECMWF model. Mon. Wea. Rev., 118, 847-873.

Neelin, J. D., and I. M. Held, 1987: Modeling tropical convergence based on the moist static energy budget. Mon. Wea. Rev., 115, 3-12.

Pinker, R., and I. Laszlo, 1992: Modeling surface solar irradiance for satellite applications on a global scale. J. Appl. Meteor., 31, 194-211.

Plana-Fattori, A., E. P. Souza, and J. C. S. Chagas, 1997: Absorption of solar radiation by water vapor in the atmosphere. Part I: A comparison between selected parameterizations and reference results. Brazil. J. Geophys., 15, 275-290.

Pope, V. D., M. L. Gallani, P. R. Rowntree, and R. A. Stratton, 2000: The impact of new physical parameterizations in the Hadley Centre climate model: HadCM3. Climate Dyn., 16, 123-146.

Potter, G. L., and R. D. Cess, 2004: Testing the impact of clouds on the radiation budgets of 19 atmospheric general circulation models. J. Geophys. Res., 109, D02106, doi:10.1029/ 2003JD004018.

Ramanathan, V., and Coauthors, 1983: The response of a spectral general circulation model to refinements in radiative processes. J. Atmos. Sci., 40, 605-630.

- R. D. Cess, E. F. Harrison, P. Minnis, B. R. Barkstrom, E. Ahmad, and D. Hartmann, 1989: Cloud-radiative forcing and climate: Results from the Earth Radiation Budget Experiment. Science, 243, 57-63.

Ramaswamy, V., and S. M. Freidenreich, 1992: A study of broadband parameterizations of the solar radiative interactions with water vapor and water drops. J. Geophys. Res., 97, 11 487-11 512.

Reynolds, R. W., and Coauthors, 2002: An improved in situ and satellite SST analysis for climate. J. Climate, 15, 1609-1625.

Rothman, L. S., and Coauthors, 1983: AFGL trace gas compilation, 1982 version. Appl. Opt., 22, 1616-1627.

- , and Coauthors, 1998: The HITRAN molecular database and HAWKS, 1996 cdition. J. Quant. Spectrosc. Radiat. Transfer, 60, 665-710.

scopic database: Edition of 2000 including 2001 updates. $J$. Quant. Spectrosc. Radiat. Transfer, 82, 5-42.

Slingo, J. M., 1987: The development of verification of a cloud prediction scheme for the ECMWF model. Quart. J. Roy. Meteor. Soc, 113, 899-927.
Souza, E. P., P. L. da S. Dias, A. Plana-Fattori, and J. C. S. Chagas, 1997: Absorption of solar radiation by water vapor in the atmosphere. Part II: Sensitivity tests with a general circulation model, Brazil. J. Geophys., 15, 291-306.

Tarasova, T., and B. Fomin, 2000: Solar radiation absorption due to water vapor: Advanced broadband parameterizations. $J$. Appl. Meteor, 39, 1947-1951.

- and 1. Cavalcanti, 2002: Monthly mean solar radiative fluxes and cloud forcing over South America in the period of 198688: GCM results and satellite-derived data. J. Appl. Meteor., 41, $863-871$.

_, H. M. J. Barbosa, and S. N. Figueroa, 2006: Incorporation of new solar radiation scheme into CPTEC GCM. Tech. Rep. INPE-14052-NTE/371, Instituto Nacional de Pesquisas Espaciais, $53 \mathrm{pp}$. [Available online at http://urlib.net/sid.inpe.br/ iris@1915/2006/01.16.10.40.]

Ticdtke, M., 1984: The effect of penetrative cumulus convection on the large-scale flow in a general circulation model. Contrib. Atmos. Phys., 57, 216-239.

Wild, M., 2005: Solar radiation budgets in atmospheric model intercomparisons from a surface perspective. Geophys. Res. Lett., 32, L07704, doi:10.1029/2005GL022421.

- and A. Ohmura, 1999: The role of clouds and the cloud-free atmosphere in the problem of underestimated absorption of solar radiation in GCM atmospheres. Phys. Chem. Earth, 24B, 261-268.

- - - H. Gilgen, and E. Roeckner, 1995: Validation of general circulation model radiative fluxes using surface observations. J. Climate, 8, 1309-1324.

_ and Coauthors, 2006: Evaluation of clear-sky solar fluxes in GCMs participating in AMIP and IPCC-AR4 from a surface perspective. J. Geophys. Res., 111, D01104, doi:10.1029/ $2005 \mathrm{JD} 006118$.

World Meteorological Organization, 1986: World Climate Research Programme: A preliminary cloudless standard atmosphere for radiation computation. WMO Tech. Doc. WCP112, WMO/TD-24, 53 pp.

Xue, Y., P. J. Sellers, J. L. Kinter IIl, and J. Shukla, 1991: A simplified biosphere model for global climate studies. J. Climate, 4, 345-364.

Yamamoto, G., 1962: Direct absorption of solar radiation by atmospheric water vapor, carbon dioxide and molecular oxygen. J. Atmos. Sci., 19, 182-188.

$\mathrm{Yu}, \mathrm{H}$, and Coauthors, 2006: A review of measurement-based assessments of the aerosol direct radiative effect and forcing. Atmos. Chem. Phys., 6, 613-666. 


\section{COPYRIGHT INFORMATION}

TITLE: Impacts of a New Solar Radiation Parameterization on the CPTEC AGCM Climatological Features

SOURCE: J Appl Meteorol Climatol 47 no5 My 2008

The magazine publisher is the copyright holder of this article and it is reproduced with permission. Further reproduction of this article in violation of the copyright is prohibited. To contact the publisher: $\mathrm{http}: / / \mathrm{www}$. ametsoc.org/AMS/ 